\title{
Farklı Gama Işını Dozlarının Macar Fiği Çeşitlerindeki Bazı Kantitatif Özelliklere Etkisi
}

\author{
Berna $\mathrm{EFE}^{1} \& \quad$ Sabahaddin ÜNAL ${ }^{2}$ \\ ${ }^{1}$ Tarla Bitkileri Merkez Araștırma Enstitüsü Müdürlüğü, Ankara \\ ${ }^{2}$ Abant İzzet Baysal Üniversitesi Ziraat ve Doğa Bilimleri Fakültesi, Bolu \\ $\bowtie$ : bernaefe85@gmail.com
}

Geliş (Received): 03.11.2017

Kabul (Accepted): 15.12.2017

\begin{abstract}
ÖZET: Mutasyon 1slahı bir ıslah programında genetik tabanı genişletmek ve özel amaçlı sslah çalışmaları için kullanılmaktadır. $\mathrm{Bu}$ ıslah metoduyla günümüze kadar pek çok başarılı sonuç alınmış ve mutant çeşitler geliştirilmiştir. Bunların bir kısmı doğrudan mutant yeni çeşitler; diğer bir kısmı da mutant bireylerin melezlemelerde kullanılması sonucunda elde edilen çeșitlerdir. Bu araştırmada, üç Macar fiği çeșidinin (Anadolu Pembesi-2002, Oğuz-2002 ve Tarm Beyazı-98) tohumlarına uygulanan dört farklı gama 1şını dozlarının M4 ve M5 bitkilerinde bazı morfolojik özellikler ve tarımsal özellik üzerine etkileri, araştırılmıştır. Doğal bitki boyu M5 bitkilerinde, ana sap uzunluğu M4 ve M5 bitkilerinde Tarm Beyazı-98'de dozlar arasındaki farklılık önemli ( $\mathrm{P}<0.05$ ve $\mathrm{P}<0.01)$ bulunurken, Oğuz-2002 ve Anadolu Pembesi-2002 çeşitlerinde dozlar arasında önemli bir farklılık saptanmamıştır. Ana sap kalınlığı ve sayısında uygulanan dozlar her üç çeşitte önemli bir değişime neden olmamıştır. Özellikle bitkideki bakla sayısı (Tarm Beyazı-98, Oğuz-2002 ve Anadolu Pembesi-2002'de kontrol ve hat ortalamaları sırayla 14.9 ve 19.4 adet; 36.5 ve 31.3 adet; 44.5 ve 28.2 adet) çeşitlere göre önemli bir değişim göstermiştir. Bir diğer önemli etki olarak Oğuz-2002 çeşidinde koltuk altında üçerli (OG602, OG605 OG801 ve OG805 hatları), Tarm Beyazı-98 çeşidinde ise üçerli ve dörderli bakla oluşumu (TB603, TB604 ve TB1006 hatları) görülmüştür. Bu iki çeşitte, gama dozları bakla sayısında (en yüksek hat ortalamaları; TB604:30.7 adet ve OG805: 60.8 adet) artış sağlarken, Anadolu Pembesi-2002 çeşidinde (en yüksek hat ortalaması; AP605: 37.8 adet) azalmalara yol açmıştır. Gama ışını uygulamalarının M4 ve M5 generasyonlarında hem incelenen bitkisel karakterler ve hem de çeşitler üzerinde farklı etkilerinin olduğu, bulunmuştur. Genel olarak M5 generasyonunda incelenen özelliklerin çoğunda farklılıkların Oğuz-2002 çeşidinde 60 ve 80 Gy, Anadolu Pembesi-2002 ile Tarm Beyazı-98 çeşitlerinde 60 ve 100 Gy dozlarda ortaya çıtı ğı belirlenmiştir.
\end{abstract}

Anahtar Kelimeler: Vicia pannonica Crantz., mutasyon ıslahı, gama ışını, M4 ve M5 bitkileri, boğumlardaki bakla sayısinin artması

\section{Effect of Different Gamma Ray Doses on Some Quantitative Characteristics in the Hungarian Vetch Varieties}

\begin{abstract}
Mutation breeding have been used for widening a genetic base and specific aimed breeding activities in a breeding program. A lot of successful results were achieved through this breeding method and mutant varieties were improved so far. Some of these are new mutant varieties, the others are varieties which result from mutant materials in using crossing technique. In this study, influences on some morphological and agronomic characteristics in plants of M4 and M5 of four different gamma ray doses applied to seed of three Hungarian vetch cultivars (Anadolu pembesi -2002, Oguz-2002 and Tarm beyaz1-98) were investigated. The natural plant height in M5 plants, the main stem height in M4 and M5 plants, there were significant differences $(\mathrm{P}<0.05$ and $\mathrm{P}<0.01)$ among the doses in Tarm beyazi-98, but there weren't in Oğuz-2002 and Anadolu pembesi-2002. The applied doses didn't cause any significant change in main stem diameter and number in all three varieties. Especially, the pod number per plant (the averages of controls and lines in Tarm Beyazı-98, Oğuz-2002 and Anadolu Pembesi-2002 are 14.9 and 19.4 number; 36.5 and 31.3 number; 44.5 and 28.2 number) showed a significant change according to varieties. Another important impact appeared as triple pod in axillary in Oğuz-2002 (OG602, OG605 OG801 and OG805 lines), triple and quadruple pod in axillary in Tarm beyazı-98 (TB603, TB604 and TB1006 lines). When gamma doses caused an increase in pod number (the highest line average: TB604:30.7 number and OG805: 60.8 number) in these two varieties, they led to decreasing in Anadolu pembesi-2002 (the highest line average: AP605: 37.8 number). It had been found that gamma ray applications had different effects on both of the observed plant characteristics and varieties in M4 and M5 generations. Emergence of the differences was generally identified on the most observed characteristics in the doses of 60 and $80 \mathrm{~Gy}$ in Oğuz-2002; in the doses of 60 and $100 \mathrm{~Gy}$ in Anadolu pembesi-2002 and Tarm beyazi- 98 .
\end{abstract}

Keywords: Vicia pannonica Crantz, mutation breeding, gamma rays, M4 and M5 plants, increased of pod number on fertile node

\section{GİRIŞ}

Bitkisel üretimde istenilen artışın sağlanması, yüksek verimli ve kaliteli çeşitler elde edilerek bunların uygun tekniklerle yetiştirilmesine bağlıdır. Yeni çeşitlerin elde edilmesi amacıyla yapılacak islah çalışmalarında uygulanan yöntemlerin başında melezleme tekniğinin geldiği bilinmektedir. Ancak, son yıllarda mutasyon tekniği de doğrudan ya da melezleme 
tekniğinin tamamlayıcısı olarak önem kazanmıştır (Akbay 1988).

Mutasyon 1slahı 1920'li yıllarda kullanılmaya başlanmıș olup son 20 yılda bitki ıslah çalıșmalarında etkisini oldukça artırmıştır. $\mathrm{Bu}$ teknikle bitki boyu, meyve uzunluğu, büyüklük, renk gibi tane özellikleri, tohumun kimyasal yapısı ve besin değerleri ile hastalık ve zararlılara dayanıklılık yönünden bitkiler geliştirilmiştir (Şehirali ve Özgen 2007).

Dünyada farklı türlerde geliştirilmiş birçok mutant çeşit bulunmaktadır. Bu çeşitlerden 3 tanesi yem bitkilerinden yaygın fiğ (Vicia sativa L.) türüne aittir ( Maluszynski ve ark., 2000). Bunlardan iki tanesi kimyasal mutagen uygulamasıyla, bir tanesi de melezlemede kullanılarak elde edilmiştir. Bu yaygın fiğ türleri yaprak genişliği, dallanma ve yaşama gücü özellikleri yönüyle geliştirilmiştir. Ayrıca, son yıllarda kimyasal mutagen uygulaması ile bakla sayısı yönüyle geliştirilmiş bir de yaygın fiğ hattı bulunmaktadır. Bu yaygın fiğ hattı kontrolle karşılaştırıldığı zaman tane verimi \% 54 oranında artmıştır (Aleksieva ve Naidevova 2012).

Mutasyon tekniği klasik 1slah yöntemlerinden daha kısa sürede varyasyon oluşturması ve islahçıya zaman kazandırması açısından önemlidir.

Bu teknikle kolay ve ucuz bir varyasyon oluşturmak, bu yeni materyal içerisinden istenilen özellikteki bitkileri seçmek mümkündür. Tohumla üretilen bitkilerde mutasyonun amacı; çeşit ya da hatta bir veya birkaç özelliği geliştirmek, çeşit tescili için tanınabilir bir morfolojik markör ortaya çıkarmaktır (Artık ve Pekșen 2006; Şehirali ve Özgen 2007). Bitkilerde mutasyon meydana getirmek için fiziksel ve kimyasal mutagenlerden yararlanılmaktadır. Fiziksel mutagenlerden en çok kullanılan gama ışın kaynakları Caesium-137 ( $\left.\mathrm{Cs}^{137}\right)$ ve Cobalt-60 ( $\left.\mathrm{Co}^{60}\right)^{\prime}$ tır. Bunun sebebi bu mutagenle meydana getirilen mutasyonların canlıda doğal olarak meydana gelen mutasyonlara çok benziyor olmasıdır (Olgun ve ark. 2012).

$\mathrm{Bu}$ çalışmada mutasyon sslahı yolu ile genetik varyasyon oluşturmak ve bu varyasyon içerisinden yeni çeşitler geliştirmek amacıyla üç Macar fiği çeşidi gama 1şınlamasına tabi tutulmuştur. Fiziksel mutagen kullanılarak elde edilen ve islah programına dahil edilen genetik materyalden $M_{4}$ ve $M_{5}$ bitkilerinde, bazı morfolojik özellikler ve tarımsal özellik üzerinde gama 1şınlarının etkileri araştırılmıştır. Mutagenlerin Macar fiği çeşitleri üzerinde uygulanmasının bazı nicel özelliklere olumlu ve olumsuz etkileri incelenmiştir.

\section{MATERYAL ve YÖNTEM}

$\mathrm{Bu}$ çalışma Tarla Bitkileri Merkez Araştırma Enstitüsü İkizce Araştırma ve Uygulama Çiftliği deneme arazisinde yürütülmüştür. Araştırmada Macar fiğ çeşitlerinden pembe çiçekli Anadolu Pembesi-2002, Oğuz- 2002 ile beyaz çiçekli Tarm Beyazı-98 materyal olarak kullanılmıştır. Ankara / Sarayköy Nükleer Araştırma ve Eğitim Merkezinde (SANAEM) bu üç Macar fiği çeşidi 1şınlama işlemine tabi tutulmuştur. Deneme materyaline 1şınlama gücü $2.190 \mathrm{kGy} /$ saat olan fiziksel mutagen $\mathrm{Co}^{60}$ kaynağı ile $0,60,80$ ve $100 \mathrm{~Gy}$ dozları uygulanmış ve bu uygulamalar bazı morfolojik gözlemlerle takip edilmiştir. 2011-2013 yılları arasında tohumların 1şınlanması, çimlendirme testleri, $\mathrm{M}_{1}, \mathrm{M}_{2}$ ile $\mathrm{M}_{3}$, aşamalarında gözlem alımı ve tek bitki seçimi çalışmaları yapılmıştır.

2013-2014 sezonunda $\mathrm{M}_{4}$ bitkileri her biri tek siraya, sıra arası mesafe $25 \mathrm{~cm}$, sıra uzunluğu ise $5 \mathrm{~m}$ olacak şekilde gözlem bahçesine ekilmiştir. Bitkiler ana sap uzunluğu (cm), ana sap sayısı (adet), bitkide bakla sayısı (adet), baklada tane sayısı (adet) bakımından gözlenmiştir.

2014-2015 sezonunda $\mathrm{M}_{5}$ bitkilerinin gözlem bahçesi parsel boyutu 2 x $0,50 \mathrm{~m} \times 3.0 \mathrm{~m}=3 \mathrm{~m}^{2}$ olacak şekilde (sıra sayısı 2, sıra arası $50 \mathrm{~cm}$, sıra boyu $3 \mathrm{~m}$ ) oluşturulmuştur. Bitkiler doğal bitki boyu $(\mathrm{cm})$, ana sap uzunluğu $(\mathrm{cm})$, ana sap kalınlığı $(\mathrm{mm})$, ana sap sayısı (adet), bitkide bakla sayısı (adet), baklada tane sayısı (adet), bakla eni $(\mathrm{mm})$ ve bakla boyu $(\mathrm{cm})$, yeşil ot verimi $\left(\mathrm{g} \mathrm{p}^{-1}=\right.$ parseldeki gram ağırlık) özellikleri yönüyle incelenmiştir.

Denemelerin yürütüldüğü Gölbaş1-İkizce lokasyonunda 2013-2014 sezonunda toplam yağış miktarı (302.2 mm) uzun yıllar ortalamasına (402.7 $\mathrm{mm}$ ) göre düşük olurken 2014-2015 sezonunda (603.0 $\mathrm{mm}$ ) fazla olmuştur. Ancak her iki yetiştirme sezonunda da bitkilerin gelişme dönemi olan Nisan ayı yağışları (2013-14;32.2 ve 2014-15;25.0 mm) uzun y1llar ortalamasının (49.3 mm) altında gerçekleşmiştir. Nisan ayında maksimum sicaklik uzun yıllar ortalaması $17.1^{\circ} \mathrm{C}$ olurken $2013-14$ 'de $26.4^{\circ} \mathrm{C}$ ve $2014-15^{\prime}$ 'de $24.0^{\circ} \mathrm{C}$ olmuştur. Ortalama sicaklık miktarı da sirasıyla 11.3, 11.9 ve $9.5^{\circ} \mathrm{C}$ olmuştur (Anonim 2016a). Araştırma yerinin toprak bünyesi ise killi-tınlı, organik madde $(1.32 \%)$ yönünden fakir, bitkiye yarayışlı fosfor $(6.37 \mathrm{~kg} / \mathrm{da})$ orta, bitkiye yarayışlı potasyum $(207.46$ $\mathrm{kg} / \mathrm{da})$ yeterli, tuzsuz $(0.02 \%)$, kireç oranı $(27.86 \%)$ çok zengin ve pH'sı (8.04) orta alkali karakterdedir (Anonim 2016b).

Çalışma sonuçları her bir çeşitteki doz uygulamalarının etkileri ve yine her bir çeşitteki mutantların değerlendirilmesi şeklinde, iki ana başlık altında ele alınmıştır. Bu şekilde hem dozların etkileri ve hem de mutantların özellikleri detaylı olarak incelenmiştir.

$\mathrm{M}_{4} \quad$ ve $\mathrm{M}_{5}$ generasyonlarındaki doz verileri RegANOVA analizi ve mutant verileri excel programı kullanilarak temel istatistik analizleri (ortalama, en düşük ve en yüksek değer, standart sapma ile değişim katsayısı ) yapılarak hesaplanmıştır.

\section{BULGULAR ve TARTIŞMA \\ Doz uygulamalarının değerlendirilmesi \\ Morfolojik özellikler}

Doz uygulamalarının her bir çeşitteki ana sap uzunluğu, ana sap sayısı, bitkideki bakla sayısı, bakladaki tane sayısı ortalama değerleri ve dozlar arasındaki önemlilik dereceleri Çizelge 1'de, doğal bitki boyu, ana sap kalınlığı, bakla eni, bakla boyu, yeşil ot verimi ortalama değerleri ve dozlar arasındaki önemlilik dereceleri Çizelge 2'de sunulmuştur. 
Çizelge 1.2014 ve 2015 yıllarında yetiştirilen macar fiği çeşitleri ve hatlarının ana sap uzunluğu, ana sap sayısı, bitki başına bakla sayısı, bakla başına tohum sayısı ortalama değerleri ve varyans analizi sonuçları

\begin{tabular}{|c|c|c|c|c|c|c|c|c|c|c|c|c|c|}
\hline \multirow{2}{*}{\multicolumn{2}{|c|}{$\begin{array}{l}\text { Tarm Beyazı-98 } \\
\text { Çeşit/Hat } \\
\text { Dozlar (Gy) }\end{array}$}} & \multicolumn{3}{|l|}{$\operatorname{ASU} \mathrm{u}^{\mathrm{x}}$} & \multicolumn{3}{|l|}{ ASS } & \multicolumn{3}{|l|}{ BBS } & \multicolumn{3}{|l|}{ BTS } \\
\hline & & 2014 & 2015 & Ort. & 2014 & 2015 & Ort. & 2014 & 2015 & Ort. & 2014 & 2015 & Ort. \\
\hline \multirow{4}{*}{ 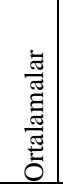 } & 0 & $37.4 \mathrm{AB}$ & $30.2 \mathrm{~B}$ & 33.8 & 1.4 & 5.0 & 3.2 & 14.8 & 15.0 & 14.9 & 4.1 & 5.2 & 4.7 \\
\hline & 60 & $37.6 \mathrm{~A}$ & $37.5 \mathrm{~B}$ & 37.6 & 1.6 & 4.8 & 3.2 & 22.2 & 19.9 & 21.1 & 5.0 & 4.6 & 4.8 \\
\hline & 80 & $32.8 \mathrm{~B}$ & $40.9 \mathrm{AB}$ & 36.8 & 1.5 & 4.9 & 3.2 & 16.0 & 17.8 & 16.9 & 4.0 & 4.3 & 4.2 \\
\hline & 100 & $32.3 \mathrm{~B}$ & $44.7 \mathrm{~A}$ & 38.5 & 1.6 & 5.1 & 3.3 & 16.3 & 24.7 & 20.5 & 4.6 & 4.8 & 4.7 \\
\hline \multicolumn{2}{|c|}{ Ortalama } & 35.0 & 38.3 & 36.7 & 1.5 & 4.9 & 3.2 & 17.3 & 19.4 & 18.4 & 4.4 & 4.7 & 4.6 \\
\hline \multicolumn{2}{|c|}{$\mathrm{F}_{(\mathrm{Doz})(0.05)}$} & $8.0^{* * *}$ & $10.6 * *$ & 1.7 & 0.1 & 0.3 & 0.2 & 1.0 & 1.0 & 0.9 & 1.8 & 1.5 & 1.5 \\
\hline \multicolumn{2}{|c|}{$\mathrm{LSD}_{(\mathrm{Doz})}(0.05)$} & 2.9 & 4.1 & 2.8 & 0.6 & 0.7 & 0.4 & 9.3 & 12.2 & 7.0 & 1.1 & 0.7 & 0.7 \\
\hline \multicolumn{2}{|c|}{$\mathrm{F}_{(\mathrm{Y} \mathrm{Il})(0.05)}$} & - & - & $57.7 * *$ & - & - & $508.5^{* *}$ & - & - & 2.1 & - & - & 0.1 \\
\hline \multicolumn{2}{|c|}{$\operatorname{LSD}_{(\mathrm{Yll})(0.05)}$} & - & - & 2.0 & - & - & 0.3 & - & - & 4.9 & - & - & 0.5 \\
\hline \multicolumn{2}{|c|}{$\mathrm{F}_{\left(\mathrm{Y}_{1}{ }^{*} \text { Doz) }(0.05)\right.}$} & - & - & $11.7 * *$ & - & - & 0.2 & - & - & 1.1 & - & - & 0.6 \\
\hline \multicolumn{2}{|c|}{$\operatorname{LSD}_{\left(\mathrm{Y}_{1} * \mathrm{Doz}\right)(0.05)}$} & - & - & 2.8 & - & - & 0.4 & - & - & 7.0 & - & - & 0.7 \\
\hline \multicolumn{2}{|c|}{$\begin{array}{l}\text { Oğuz-2002 } \\
\text { Çeşit/Hat }\end{array}$} & \multicolumn{3}{|l|}{ ASU } & \multicolumn{3}{|l|}{ ASS } & \multicolumn{3}{|l|}{ BBS } & \multicolumn{3}{|l|}{ BTS } \\
\hline \multicolumn{2}{|c|}{ Dozlar (Gy) } & 2014 & 2015 & Ort. & 2014 & 2015 & Ort. & 2014 & 2015 & Ort. & 2014 & 2015 & Ort. \\
\hline & 0 & 17.2 & 13.3 & 15.2 & 1.4 & 3.6 & 2.5 & $\begin{array}{l}17.0 \\
\text { A }\end{array}$ & 56.0 & 36.5 & 1.7 & 1,8 & 1.8 \\
\hline & 60 & 16.2 & 16.6 & 16.4 & 2.0 & 3.4 & 2.7 & $\begin{array}{l}30.0 \\
\text { B }\end{array}$ & 44.5 & 37.2 & 2.3 & 1.8 & 2.1 \\
\hline 点 & 80 & 16.2 & 17.6 & 16.9 & 1.4 & 3.7 & 2.6 & $\begin{array}{l}20.4 \\
\text { A }\end{array}$ & 55,4 & 37.9 & 2.8 & 2.0 & 2.4 \\
\hline$\frac{\pi}{\tilde{\sigma}}$ & 100 & 15.7 & 17.7 & 16.7 & 1.7 & 4.1 & 2.9 & $\begin{array}{l}18.3 \\
C\end{array}$ & 32,7 & 25.5 & 2.0 & 2.1 & 2.0 \\
\hline \multicolumn{2}{|c|}{ Ortalama } & 16.3 & 16.3 & 16.3 & 1.6 & 3.7 & 2.7 & 21.4 & 47.2 & 34.3 & 2.2 & 1.9 & 2.1 \\
\hline \multicolumn{2}{|c|}{$\mathrm{F}_{\text {(Dozlar) (0.05) }}$} & 1.1 & 1.0 & 0.4 & 1.6 & 1.0 & 1.0 & $\begin{array}{l}11.2 * \\
*\end{array}$ & 1.1 & 1.9 & 2.4 & 0.6 & 1.4 \\
\hline \multicolumn{2}{|c|}{ LSD $_{\text {(Dozlar) (0.05) }}$} & 1.2 & 3.4 & 1.7 & 0.6 & 1.0 & 0.5 & 5.1 & 34.9 & 14.6 & 0.9 & 0.5 & 0.5 \\
\hline \multicolumn{2}{|c|}{$\mathrm{F}_{(\mathrm{Yll})(0.05)}$} & - & - & $4.4^{*}$ & - & - & $139.9 * *$ & - & - & $\begin{array}{l}16.8^{*} \\
*\end{array}$ & - & - & 1.6 \\
\hline LSD & $(\mathrm{Yll})(0.05)$ & - & - & 1.2 & - & - & 0.4 & - & - & 10.3 & - & - & 0.3 \\
\hline $\mathrm{F}_{(\mathrm{Yll}}$ & ${ }^{*}$ Doz) $(0.05)$ & - & - & 0.4 & - & - & 1.3 & - & - & 1.2 & - & - & 2.0 \\
\hline LSD & $\left(\mathrm{Y}_{\mathrm{Y}}^{*} \mathrm{*}\right.$ Doz $)(0,05)$ & - & - & 1.7 & - & - & 0.5 & - & - & 14.6 & - & - & 0.5 \\
\hline $\begin{array}{l}\text { Anac } \\
2002 \\
\end{array}$ & $\begin{array}{l}\text { dolu Pembesi- } \\
2 \text { Çeşit/Hat }\end{array}$ & ASU & & & ASS & & & BBS & & & BTS & & \\
\hline Dozl & $\operatorname{ar}(\mathrm{Gy})$ & 2014 & 2015 & Ort. & 2014 & 2015 & Ort. & 2014 & 2015 & Ort. & 2014 & 2015 & Ort. \\
\hline & 0 & 17.2 & 18.9 & 18.0 & $2.0 \mathrm{~A}$ & 5.0 & 3.5 & $\begin{array}{l}26.3 \\
\text { A }\end{array}$ & 62.6 & 44.5 & $2.0 \mathrm{C}$ & 1.8 & 1.9 \\
\hline & 60 & 15.0 & 20.1 & 17.5 & $\begin{array}{l}1.3 \\
\mathrm{AB}\end{array}$ & 3.3 & 2.3 & $\begin{array}{l}24.2 \\
\text { B }\end{array}$ & 41.3 & 32.8 & $2.2 \mathrm{~A}$ & 2.4 & 2.3 \\
\hline 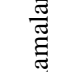 & 80 & 15.8 & 17.6 & 16.7 & $\begin{array}{l}1.4 \\
\mathrm{AB}\end{array}$ & 3.4 & 2.4 & $\begin{array}{l}19.7 \\
\text { B }\end{array}$ & 38.5 & 29.1 & $\begin{array}{l}1.8 \\
\mathrm{BC}\end{array}$ & 1.9 & 1.9 \\
\hline 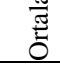 & 100 & 16.2 & 19.5 & 17.7 & $1.0 \mathrm{~B}$ & 4.6 & 2.8 & $\begin{array}{l}12.9 \\
\text { B }\end{array}$ & 36.2 & 24.5 & $1.8 \mathrm{~B}$ & 2.0 & 1.9 \\
\hline Orta & lama & 16.1 & 19.0 & 17.5 & 1.4 & 4.1 & 2.8 & 20.8 & 44.7 & 32.7 & 2.0 & 2.0 & 2.0 \\
\hline $\mathrm{F}_{(\mathrm{Do}}$ & zlar) (0.05) & 0.6 & 0.4 & 1.5 & $5.9^{* *}$ & 1.0 & 1.4 & $7.2 *$ & 2.2 & 2.6 & $\begin{array}{l}21.8^{*} \\
*\end{array}$ & 0.6 & 1.5 \\
\hline LSD & (Dozlar) (0.05) & 3.3 & 7.5 & 0.5 & 0.5 & 2.8 & 0.9 & 7.6 & 20.7 & 11.3 & 0.2 & 1.1 & 0.5 \\
\hline $\mathrm{F}_{(\mathrm{Yll})}$ & $(0.05)$ & - & - & 0.5 & - & - & $70.3 * *$ & - & - & $\begin{array}{l}34.4^{*} \\
*\end{array}$ & - & - & 0.5 \\
\hline LSD & $(\mathrm{YII})(0.05)$ & - & - & 0.3 & - & - & 0.7 & - & - & 8.0 & - & - & 0.3 \\
\hline $\mathrm{F}_{(\mathrm{Yll}}$ & ${ }^{* \text { Doz) }(0.05)}$ & - & - & 0.2 & - & - & 1.8 & - & - & 0.6 & - & - & 0.2 \\
\hline LSD & $\left(\mathrm{Yl}_{1}{ }^{*} \mathrm{Doz}\right)(0.05)$ & - & - & 0.5 & - & - & 0.9 & - & - & 11.3 & - & - & 0.5 \\
\hline
\end{tabular}

x: ASU: Ana Sap Uzunluğu (cm), ASS: Ana Sap Sayısı (Adet), BBS: Bitkideki Bakla Sayısı (Adet), BTS: Bakladaki Tane Sayısı (Adet)

X: ASU: Main stem length (cm), ASS: Main stem number, BBS: Pod number in the plant, BTS: Grain number in the plant

$*: 0.05$ düzeyinde önemli, **:0.01 düzeyinde önemli

$*$ :Significant at $p<0.05, * *$ :Significant at $p<0.01$ 
Çizelge 2. Macar fiği çeşitleri ve hatlarına ait 2015 yılı doğal bitki boyu, ana sap kalınlığı, bakla eni, bakla boyu ortalama değerleri ve analiz sonuçları

\begin{tabular}{|c|c|c|c|c|c|c|}
\hline \multirow{2}{*}{\multicolumn{2}{|c|}{$\begin{array}{l}\text { Tarm Beyazı-98 Çeşit/Hat } \\
\text { Dozlar (Gy) }\end{array}$}} & \multirow{2}{*}{$\mathrm{DBB}^{\mathrm{xx}},{ }^{\mathrm{xxx}}$} & \multirow{2}{*}{ ASK } & \multirow{2}{*}{$\mathrm{BE}$} & \multirow{2}{*}{$\mathrm{BB}$} & \multirow{2}{*}{ YOV } \\
\hline & & & & & & \\
\hline z & 0 & $19.5 \mathrm{~B}$ & 2.3 & 7.0 & 2.6 & $655.0 \mathrm{C}$ \\
\hline $\bar{\Xi}$ & 60 & $27.7 \mathrm{AB}$ & 2.2 & 6.8 & 2.7 & $780.0 \mathrm{BC}$ \\
\hline$\frac{\bar{\pi}}{\pi}$ & 80 & $29.4 \mathrm{AB}$ & 2.1 & 7.4 & 2.9 & $867.1 \mathrm{AB}$ \\
\hline$\stackrel{\square}{0}$ & 100 & $31.8 \mathrm{~A}$ & 2.2 & 7.2 & 3.0 & $1017.2 \mathrm{~A}$ \\
\hline \multicolumn{2}{|c|}{ Ortalama } & 27.1 & 2.2 & 7.1 & 2.8 & 829.8 \\
\hline \multicolumn{2}{|c|}{$\mathrm{F}_{(\mathrm{Doz})(0.05)}$} & $4.8^{*}$ & 1.0 & 3.3 & 3.0 & $4.6^{*}$ \\
\hline \multicolumn{2}{|c|}{$\mathrm{LSD}_{(\mathrm{Doz})}(0.05)$} & 4.6 & 0.2 & 0.5 & 0.2 & 185.5 \\
\hline \multicolumn{2}{|c|}{ Oğuz-2002 Çeşit/Hat } & & & & & \\
\hline \multicolumn{2}{|c|}{ Dozlar (Gy) } & DBB & ASK & $\mathrm{BE}$ & BB & YOV \\
\hline $\bar{z}$ & 0 & 6.1 & 1.8 & 7.0 & 2.0 & 125.0 \\
\hline $\bar{\Xi}$ & 60 & 8.8 & 1.8 & 6.9 & 2.2 & 197.5 \\
\hline$\frac{\bar{\pi}}{\pi}$ & 80 & 8.1 & 1.9 & 6.8 & 2.3 & 119.2 \\
\hline$\ddot{0}$ & 100 & 7.6 & 1.8 & 7.1 & 2.2 & 120.4 \\
\hline \multicolumn{2}{|c|}{ Ortalama } & 7.6 & 1.8 & 6.9 & 2.2 & 140.5 \\
\hline \multicolumn{2}{|c|}{$\mathrm{F}_{\text {(Dozlar) }(0.05)}$} & 0.6 & 0.9 & 1.4 & 1.0 & 0.6 \\
\hline \multicolumn{2}{|c|}{ LSD $_{\text {(Dozlar) }(0.05)}$} & 2.5 & 0.1 & 0.5 & 0.2 & 128.0 \\
\hline \multicolumn{2}{|c|}{$\begin{array}{ll}\text { Anadolu } & \text { Pembesi-2002 } \\
\text { Çeşit/Hat } & \\
\end{array}$} & DBB & ASK & $\mathrm{BE}$ & BB & YOV \\
\hline \multicolumn{7}{|c|}{ Dozlar (Gy) } \\
\hline \multirow{4}{*}{ 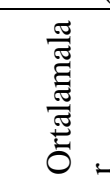 } & 0 & 8.3 & 1.9 & 7.0 & 2.1 & 130.0 \\
\hline & 60 & 9.6 & 1.8 & 7.0 & 2.3 & 90.0 \\
\hline & 80 & 8.9 & 1.7 & 6.7 & 2.1 & 77.5 \\
\hline & 100 & 7.4 & 1.9 & 6.8 & 2.3 & 72.5 \\
\hline \multicolumn{2}{|c|}{ Ortalama } & 8.5 & 1.8 & 6.9 & 2.2 & 92.5 \\
\hline \multicolumn{2}{|c|}{$\mathrm{F}_{\text {(Dozlar) }(0.05)}$} & 2.6 & 4.9 & 0.2 & 1.7 & 0.9 \\
\hline \multicolumn{2}{|c|}{$\mathrm{LSD}_{\text {(Dozlar) }(0.05)}$} & 2.2 & 0.2 & 1.3 & 0.3 & 73.4 \\
\hline
\end{tabular}

xx: DBB: Doğal Bitki Boyu (cm), ASK: Ana Sap Kalınlığı (mm), BE: Bakla Eni (mm), BB: Bakla Boyu (cm), YOV: Yeşil Ot Verimi $\left(\mathrm{g} \mathrm{p}^{-1}\right)$

${ }^{x x}$ : DBB:Natural plant height (cm), ASK:Main Stem Thickness (mm), BE:Broad Width (mm) BB:Broad Height (cm), YOV:Green grass yield ( $g$ / plot)

xxx:2015 yilında incelenmiştir

$x x x$ : It was explored in 2015

\section{Doğal bitki boyu (DBB, cm)}

DBB $\mathrm{M}_{5}$ bitkilerinde incelenmiş, Tarm Beyazı-98 çeşidinde dozlar arasındaki farklılık önemli $(\mathrm{P}<0.05)$ bulunmuştur. Aynı çeşitte gama 1şın dozunun artışıyla DBB da artış görülmüştür. Oğuz-2002 ve Anadolu Pembesi-2002 çeşitlerinde dozlar arasında önemli bir farklılık saptanmamıştır (Çizelge 2).

Çizelge 1. Macar fiği çeşitleri ve hatlarına ait 2014 ve 2015 yılları ana sap uzunluğu, ana sap sayısı, bitkideki bakla sayısı, bakladaki tane sayısı ortalama değerleri ve varyans analiz sonuçları

\section{Ana sap uzunluğu (ASU, cm)}

$\mathrm{Bu}$ özellik açısından yalnızca Tarm Beyazı-98 çeşidinde $\mathrm{M}_{4}$ ve $\mathrm{M}_{5}$ bitkilerinde dozlar arası önemli farklılı bulunmuştur $(\mathrm{P}<0.01)$. Tarm Beyazı-98 çeşidinde y1l ve $\mathrm{yl}_{1} \mathrm{doz}_{\mathrm{d}}$ interaksiyonu önemli bulunmuştur $(\mathrm{P}<0.01)$. Ayrıca artan doz oranı, ASU artışına sebep olmuştur. Buna ilaveten uygulamalardan 60 ve 100 Gy doz en iyi sonuçları vermiştir (Çizelge 1).

Ana sap kalınlığı (ASK, mm)

$\mathrm{Bu}$ özellik yönünden tüm çeşitlerde dozlar arası fark önemli olmamıştır (Çizelge 2).

Ana sap sayısı (ASS, adet)

ASS incelenen çeşitlerde dozlar arası önemli bir farklılık olmazken her üç çeşitte de yıllar arası fark istatiksel olarak önemli olmuştur $(\mathrm{P}<0.01)$ (Çizelge 1).

Bitkide bakla sayısı (BBS, adet)

Çeşitlerin $\mathrm{M}_{4}$ ve $\mathrm{M}_{5}$ bitkilerinde BBS bakımından dozlar arasında önemli bir fark bulunmazken Oğuz2002 ve Anadolu Pembesi-2002 çeşitlerinde yıllar arası fark önemli bulunmuştur $(\mathrm{P}<0.01)$ (Çizelge 1).

Doz uygulamaları çeşitler de farklı etki yapmış olup Anadolu Pembesi-2002 çeşidinde düşüşe, Tarm Beyazı98 çeşidinde ise artışa sebep olmuştur. Oğuz-2002 çeşidinde ise dozlara göre artış ve düşüş görülmüştür (60 ve 80 Gy dozlarda artış, 100 Gy dozda düşüş).

\section{Baklada tane sayısı (BTS, adet)}

Tüm çeşitlerde BTS $\mathrm{M}_{4}$ ve $\mathrm{M}_{5}$ generasyonlarında dozlar arasındaki fark önemli bulunmamıştır (Çizelge 1).

Bakla eni (BE, mm) ve bakla boyu (BB, cm)

Her iki özellik BE ve BB açısından $\mathrm{M}_{5}$ 
generasyonunda dozlar arasında önemli bir fark bulunmamış̧ır (Çizelge 2). Uygulanan dozların çeşitler üzerinde etkileri farklı olmuştur. Oğuz-2002 çeşidinde 100 Gy, Tarm Beyazı- 98 çeşidinde ise 80 ve 100 Gy dozlarda BE artırmış, Anadolu Pembesi-2002 çeşidinde ise tüm dozlar azalma görülmüştür.

BB bakımından ise dozlar Anadolu Pembesi-2002 ile Oğuz-2002 çeşitlerini etkilememiş, Tarm Beyazı-98 çeşidinde ise $100 \mathrm{~Gy}$ doz artışa sebep olmuştur (Çizelge 2,4 ve 6 ).

\section{Tarımsal özellik}

Yeşil ot verimi (YOV, $\mathrm{g} \mathrm{p}^{-1}$ )

Dozlar YOV açısından çeşitler üzerinde farklı etki yapmıştır. Tarm Beyazı-98'de $\mathrm{M}_{5}$ generasyonunda önemli farklılık tespit edilmiştir $(\mathrm{P}<0.05)$ (Çizelge 2$)$. $\mathrm{Bu}$ çeşitte doz artışıla verim artışı da görülmüş̧ür.

Oğuz-2002 ve Anadolu Pembesi-2002 çeşitlerinde doz uygulamaları arası fark bulunmamış ancak Oğuz2002 çeşidinde 60 Gy doz YOV artmaya 80 ve 100 Gy uygulamaları ise azalmaya yol açmıştır. Bunun yanında Anadolu Pembesi-2002'de ise doz artı̧̧ ile YOV azalmıştır (Çizelge 2).

Doz uygulamalarının çeşitler üzerindeki etkileri özelliklere göre farklılık göstermiştir. $\mathrm{Bu}$ araştırma sonuçları, bakla bitkisi çeşitleri ile hattı üzerinde çalışan ve uygulanan gama işını dozlarının $\mathrm{M}_{2}$ generasyonundaki bitkilerde farklı etkilerinin olduğunu saptayan Atık ve Pekşen (2006) ile Olgun ve ark. (2012)'nın gama ışını uygulamalarının etkisini inceledikleri iki ekmeklik buğday çeşidi üzerindeki bulgularıla benzerlik göstermektedir. Ayrıca elde edilen veriler, susam bitkisi üzerinde farklı gama 1şın dozlarının bitkinin çeşitli kantitatif özelliklerinde varyasyon oluşturmak için başarıyla kullanılabileceğini ifade eden Ramados ve ark. (2014)'nın bulguları ile uyum sağlamaktadır.

Çizelge 3. Tarm Beyazı-98 çeşidi ve mutantların 2014 ve 2015 yılları ana sap uzunluğu, ana sap sayısı, bitkideki bakla sayısı, bakladaki tane sayısı, doğal bitki boyu, ana sap kalınlığı, bakla eni, bakla boyu, yeşil ot verimi değerleri ile basit istatistik analiz sonuçları

\begin{tabular}{|c|c|c|c|c|c|c|c|c|c|c|c|c|c|c|c|c|c|c|c|}
\hline \multirow{2}{*}{ No } & \multirow{2}{*}{ Çeşit / Hat } & & \multicolumn{3}{|l|}{ ASU } & \multicolumn{3}{|l|}{ ASS } & \multicolumn{3}{|l|}{ BBS } & \multicolumn{3}{|l|}{ BTS } & \multirow{2}{*}{\begin{tabular}{|l|} 
DBB \\
2015 \\
\end{tabular}} & \multirow{2}{*}{\begin{tabular}{|l|} 
ASK \\
2015 \\
\end{tabular}} & \multirow{2}{*}{$\begin{array}{l}\mathrm{BE} \\
2015\end{array}$} & \multirow{2}{*}{$\begin{array}{l}\text { BB } \\
2015\end{array}$} & \multirow{2}{*}{\begin{tabular}{|l|} 
YOV \\
2015
\end{tabular}} \\
\hline & & & 2014 & 2015 & Ort. & 2014 & 2015 & Ort. & 2014 & 2015 & Ort. & 2014 & 2015 & Ort. & & & & & \\
\hline 1 & $\begin{array}{l}\text { Tarm } \\
\text { Beyaz1-98 }\end{array}$ & & 37.4 & 30.2 & 33.8 & 1.4 & 5.0 & 3.2 & 14.8 & 15.0 & 14.9 & 4.1 & 5.2 & 4.7 & 19.5 & 2.3 & 7.0 & 2.6 & 655.0 \\
\hline 2 & TB601*** & & 39.8 & 29.6 & 34.7 & 1.0 & 4.6 & 2.8 & 17.8 & 11.2 & 14.5 & 5.0 & 4.0 & 4.5 & 19.8 & 2.1 & 7.0 & 2.4 & 535.0 \\
\hline 3 & TB602 & & 39.9 & 42.0 & 41.0 & 1.6 & 5.2 & 3.4 & 15.0 & 16.2 & 15.6 & 6.6 & 4.4 & 5.5 & 30.1 & 2.2 & 6.6 & 2.7 & 855.0 \\
\hline 4 & TB603 & & 38.7 & 37.9 & 38.3 & 1.2 & 5.0 & 3.1 & 19.0 & 31.4 & 25.2 & 4.0 & 5.6 & 4.8 & 27.2 & 2.3 & 6.6 & 3.1 & 670.0 \\
\hline 5 & TB604 & & 35.0 & 33.8 & 34.4 & 3.0 & 4.0 & 3.5 & 45.4 & 16.0 & 30.7 & 4.8 & 3.8 & 4.3 & 26.8 & 2.1 & 6.6 & 2.5 & 745.0 \\
\hline 6 & TB605 & & 34.4 & 44.4 & 39.4 & 1.4 & 5.2 & 3.3 & 13.8 & 24.8 & 19.3 & 4.8 & 5.2 & 5.0 & 34.4 & 2.3 & 7.0 & 2.8 & 1095.0 \\
\hline 7 & TB801 & & 33.2 & 38.4 & 35.8 & 1.2 & 5.0 & 3.1 & 10.2 & 14.6 & 12.4 & 1.8 & 3.8 & 2.8 & 25.6 & 2.2 & 6.8 & 2.6 & 665.0 \\
\hline 8 & TB802 & & 31.3 & 37.9 & 34.6 & 1.4 & 4.4 & 2.9 & 14.2 & 32.8 & 23.5 & 5.6 & 3.2 & 4.4 & 24.6 & 2.2 & 7.4 & 2.7 & 790.0 \\
\hline 9 & TB803 & & 34.6 & 35.9 & 35.3 & 1.8 & 4.8 & 3.3 & 19.4 & 12.2 & 15.8 & 3.6 & 4.8 & 4.2 & 27.1 & 2.0 & 7.4 & 3.0 & 500.0 \\
\hline 10 & TB804 & & 32.5 & 38.9 & 35.7 & 1.4 & 4.6 & 3.0 & 15.8 & 10.4 & 13.1 & 4.6 & 3.8 & 4.2 & 28.2 & 2.0 & 7.0 & 2.7 & 785.0 \\
\hline 11 & TB805 & & 34.2 & 45.8 & 40.0 & 1.6 & 5.6 & 3.6 & 15.4 & 22.2 & 18.8 & 3.0 & 5.0 & 4.0 & 34.4 & 2.2 & 8.4 & 3.2 & 1165.0 \\
\hline 12 & TB806 & & 31.7 & 44.1 & 37.9 & 1.2 & 5.0 & 3.1 & 18.0 & 14.0 & 16.0 & 5.2 & 4.2 & 4.7 & 31.8 & 2.1 & 7.8 & 3.3 & 1040.0 \\
\hline 13 & TB807 & & 32.0 & 45.0 & 38.5 & 2.2 & 5.0 & 3.6 & 19.0 & 18.6 & 18.8 & 4.4 & 5.2 & 4.8 & 34.0 & 2.0 & 7.2 & 3.0 & 1125.0 \\
\hline 14 & TB1001 & & 30.1 & 40.4 & 35.3 & 1.6 & 4.4 & 3.0 & 14.4 & 38.8 & 26.6 & 3.8 & 4.8 & 4.3 & 28.6 & 2.5 & 7.0 & 3.0 & 560.0 \\
\hline 15 & TB1002 & & 29.3 & 49.0 & 39.2 & 1.2 & 5.4 & 3.3 & 17.2 & 22.0 & 19.6 & 5.8 & 4.6 & 5.2 & 37.4 & 2.4 & 6.8 & 3.0 & 1270.0 \\
\hline 16 & TB1003 & & 29.3 & 42.6 & 36.0 & 1.2 & 6.0 & 3.6 & 13.4 & 16.8 & 15.1 & 4.2 & 4.8 & 4.5 & 33.6 & 2.0 & 7.2 & 3.0 & 660.0 \\
\hline 17 & TB1004 & & 30.7 & 44.2 & 37.5 & 1.8 & 5.6 & 3.7 & 16.8 & 22.0 & 19.4 & 4.6 & 4.0 & 4.3 & 32.2 & 2.4 & 6.8 & 2.7 & 1035.0 \\
\hline 18 & TB1005 & & 32.9 & 44.8 & 38.9 & 1.8 & 4.8 & 3.3 & 17.4 & 18.2 & 17.8 & 5.2 & 3.8 & 4.5 & 31.4 & 2.3 & 7.0 & 2.8 & 1065.0 \\
\hline 19 & TB1006 & & 32.4 & 45.6 & 39.0 & 1.4 & 4.8 & 3.1 & 20.2 & 21.4 & 20.8 & 4.0 & 4.6 & 4.3 & 29.9 & 2.1 & 7.8 & 3.0 & 965.0 \\
\hline 20 & TB1007 & & 32.2 & 48.2 & 40.2 & 1.6 & 4.6 & 3.1 & 16.2 & 21.2 & 18.7 & 4.6 & 5.0 & 4.8 & 34.8 & 2.1 & 7.6 & 3.0 & 1425.0 \\
\hline 21 & TB1008 & & 36.3 & 45.3 & 40.8 & 2.0 & 5.2 & 3.6 & 17.4 & 38.8 & 28.1 & 4.4 & 4.6 & 4.5 & 31.2 & 2.1 & 7.0 & 2.9 & 1320.0 \\
\hline 22 & TB1009 & & 37.2 & 42.4 & 39.8 & 1.8 & 4.8 & 3.3 & 13.6 & 23.0 & 18.3 & 4.8 & 6.6 & 5.7 & 27.4 & 2.1 & 7.8 & 3.3 & 855.0 \\
\hline \multicolumn{3}{|c|}{ Ortalama } & 33.7 & 41.7 & 37.7 & 1.6 & 5.0 & 3.3 & 17.6 & 21.3 & 19.4 & 4.5 & 4.6 & 4.5 & 30.0 & 2.2 & 7.2 & 2.9 & 910.7 \\
\hline \multicolumn{3}{|c|}{ En Düşük Değer : } & 29.3 & 29.6 & 34.4 & 1.0 & 4.0 & 2.8 & 10.2 & 10.4 & 12.4 & 1.8 & 3.2 & 2.8 & 19.8 & 2.0 & 6.6 & 2.4 & 500.0 \\
\hline \multicolumn{3}{|c|}{$\begin{array}{ll}\text { En } & \text { Yüksek } \\
\text { Değer } & \end{array}$} & 39.9 & 49.0 & 41.0 & 3.0 & 6.0 & 3.7 & 45.4 & 38.8 & 30.7 & 6.6 & 6.6 & 5.7 & 37.4 & 2.5 & 8.4 & 3.3 & 1425.0 \\
\hline \multicolumn{3}{|c|}{ Standart Sapma : } & 3.2 & 4.9 & 2.2 & 0.4 & 0.5 & 0.3 & 6.8 & 8.2 & 4.9 & 1.0 & 0.8 & 0.6 & 4.2 & 0.1 & 0.5 & 0.2 & 268.6 \\
\hline \multicolumn{3}{|c|}{$\begin{array}{l}\text { Değişim } \\
\text { Katsayısı (\%) }\end{array}$} & 9.4 & 11.7 & 5.8 & 28.0 & 9.4 & 7.9 & 38.7 & 38.7 & 25.3 & 22.3 & 16.7 & 13.0 & 13.9 & 6.9 & 6.6 & 8.3 & 29.5 \\
\hline
\end{tabular}


Çizelge 4. Oğuz-2002 çeşidi ve mutantların 2014 ve 2015 yılları ana sap uzunluğu, ana sap sayısı, bitkideki bakla sayısı, bakladaki tane sayısı, doğal bitki boyu, ana sap kalınlığı, bakla eni, bakla boyu, yeşil ot verimi değerleri ile basit istatistik analiz sonuçları

\begin{tabular}{|c|c|c|c|c|c|c|c|c|c|c|c|c|c|c|c|c|c|c|}
\hline \multirow{2}{*}{ No } & \multirow{2}{*}{ eşit / Hat } & \multicolumn{3}{|l|}{$\mathrm{ASU}$} & \multicolumn{3}{|l|}{ ASS } & \multicolumn{3}{|l|}{ BBS } & \multicolumn{3}{|l|}{ BTS } & \multirow{2}{*}{$\begin{array}{l}\text { DBB } \\
2015 \\
\end{array}$} & \multirow{2}{*}{$\begin{array}{ll}\text { ASK } \\
2015 \\
\end{array}$} & \multirow{2}{*}{\begin{tabular}{|l|}
$\mathrm{BE}$ \\
2015 \\
\end{tabular}} & \multirow{2}{*}{$\begin{array}{l}\mathrm{BB} \\
2015\end{array}$} & \multirow{2}{*}{$\begin{array}{l}\text { YOV } \\
2015\end{array}$} \\
\hline & & 2014 & 2015 & Ort. & 2014 & 2015 & Ort. & 2014 & 2015 & Ort. & 2014 & 2015 & Ort. & & & & & \\
\hline 1 & & 17.2 & 13.3 & 15.2 & 1.4 & 3.6 & 2.5 & 17.0 & 56.0 & 36.5 & 1.7 & 1.8 & 1.8 & 6.1 & 1.8 & 7.0 & 2.0 & 125.0 \\
\hline 2 & $\mathrm{~s} 601$ & & 18.1 & 6 & 4 & 3.8 & 2.6 & 28.2 & 6.2 & 27.2 & 3.0 & 1.6 & 2.3 & 7.6 & 1.8 & 7.2 & 2 & 133.7 \\
\hline 3 & & .3 & 16.0 & 14.7 & 4 & 4.4 & 3.4 & 38.0 & 31.8 & 34.9 & 2.2 & 2.4 & 2.3 & 8.2 & 1.8 & 7.0 & .2 & 275.0 \\
\hline 4 & & .5 & 15.9 & 5.7 & & 3.6 & 2.6 & 26.4 & 54.0 & 40.2 & 2.4 & 1.6 & 2.0 & 7.6 & 1.8 & 7.0 & 2.2 & 145.0 \\
\hline 5 & & 8 & 14.8 & 5.8 & 6 & 2.4 & 2.5 & 31.2 & 25.8 & 28.5 & 1.8 & 2.2 & 2.0 & 8.9 & 1.5 & 6.8 & 2.3 & 115.0 \\
\hline 6 & & 3 & 18.3 & .3 & 0 & 3.2 & 2.6 & 26.0 & 84.6 & 55.3 & 2.2 & 1.6 & 1.9 & 10.4 & 1.9 & 6.6 & 2.2 & 255.0 \\
\hline 7 & & & 15.7 & & & 3.0 & 2.3 & 18.0 & 7.6 & 42.8 & 5.2 & 2.4 & 3.8 & 7.8 & 1.9 & 7.0 & 2.3 & 25.0 \\
\hline 8 & & .1 & 18.8 & 17.0 & & 3.6 & 2.8 & 31.4 & 38.8 & 35.1 & 2.0 & 1.6 & 1.8 & 10.5 & 1.9 & 6.8 & 2.2 & 350.0 \\
\hline 9 & & & 13.1 & .1 & & 3.8 & 2.5 & 20.2 & 28.4 & 24.3 & 2.2 & 1.8 & 2.1 & 6.0 & 1.8 & 6.6 & 2.1 & 40.0 \\
\hline 10 & & & 18.0 & 7.6 & & 4 & 8 & 21.4 & 100.2 & 60.8 & 2.6 & 2. & 2.5 & 6. & 1.8 & 6.4 & 2.2 & 85.0 \\
\hline 11 & & & 19.7 & $\begin{array}{l}18.9 \\
\end{array}$ & 0 & 3.2 & 2.1 & 17.4 & 43.0 & 30.2 & 2.0 & 1.8 & 1.9 & 8.2 & 1.9 & 6.6 & 2.2 & 65.0 \\
\hline 12 & & .3 & 20.1 & 17.2 & 2 & 4.4 & 2.8 & 13.8 & 54.6 & 34.2 & 2.6 & 2.0 & 2.3 & 9.2 & 1.8 & 7.2 & 2.7 & 150.0 \\
\hline 13 & & .4 & 20.2 & 17.8 & 2 & 5.2 & 3.2 & 15.6 & 22.0 & 18.8 & 2.2 & 1. & 1.8 & 7.9 & 2.0 & 6.6 & 2.1 & 170.0 \\
\hline 14 & & .1 & 19.3 & 17.7 & & 4.0 & 3.2 & 35.6 & 47.4 & 41.5 & 2.2 & 2. & 2. & 8.2 & 1.9 & 7.0 & 2.1 & 140.0 \\
\hline 15 & & .7 & 16.8 & 16.8 & & 3.4 & 3.1 & 30.2 & 39.8 & 35.0 & 2.0 & 2. & 2. & 9.3 & 1.8 & 6.4 & 2.2 & 120.0 \\
\hline 16 & & & 18 & & & 3. & 2. & 30.0 & 19.6 & 24.8 & 1.6 & 2. & 2. & 10.4 & 1.7 & 7.0 & 2.5 & 295.0 \\
\hline 17 & & & 13.6 & & & 4.0 & 2.6 & 13.2 & 15.6 & 14.4 & 1.8 & 2.0 & 1.9 & 4.9 & 1.7 & 7.6 & 2.5 & 35.0 \\
\hline 18 & & 4 & 15.6 & 15.0 & 1.8 & 3.4 & 2.6 & 13.4 & $\begin{array}{l}3.8 \\
\end{array}$ & \begin{tabular}{|l|}
13.6 \\
\end{tabular} & 1.8 & 2.2 & 2.0 & 6.6 & 1.8 & 8.0 & 2.4 & 80.0 \\
\hline 19 & & 6 & 12.9 & 14.3 & 1.2 & 3.0 & 2.1 & 13.8 & 10.0 & 11.9 & 2.0 & 1.8 & 1.9 & 4.6 & 1.8 & 7.4 & 2.1 & 25.0 \\
\hline 20 & & & 18.5 & & & 4.2 & 3.7 & 21.8 & 42.6 & & 2.0 & 3. & 2. & 7.9 & 1.8 & 7.0 & 2.4 & 120.0 \\
\hline 21 & & & 18.0 & & & 5 & 3.2 & 11.8 & .3 & 23 & 1.8 & 2. & 1. & 8.3 & 1.9 & 7.8 & 2.2 & 75.0 \\
\hline$\overline{22}$ & & & 20.0 & 17.8 & & 5.0 & 3.2 & 8.2 & 41.0 & 24.6 & 2.0 & 1.8 & 1.9 & 6.1 & 1.8 & 6.6 & 2.1 & 70.0 \\
\hline 23 & & & 18.1 & 16.5 & & 4.2 & 2. & 1.8 & 33.4 & 23.1 & 2.4 & 2. & 2.4 & 9.9 & 1.8 & 6.8 & 2.2 & 205.0 \\
\hline 24 & OG10012 & 14.1 & 20.0 & 17.1 & & 4.4 & 2.8 & 12.6 & 71.6 & 42.1 & 1.6 & 2.2 & 1.9 & 7.4 & 1.8 & 7.4 & 2.2 & 110.0 \\
\hline \multicolumn{2}{|c|}{ Ortalama } & 15.9 & 17.4 & 16.7 & 1.7 & 3.9 & 2.8 & 20.9 & 41.2 & 31.3 & 2.2 & 2.0 & 2.1 & 7.9 & 1.8 & 7.0 & 2.2 & 134.1 \\
\hline \multicolumn{2}{|c|}{ En Düşük Değer : } & 13.3 & 12.9 & 14.3 & 1.0 & 2.4 & 2.1 & 1.8 & 10.0 & 11.9 & 1.6 & 1.4 & 1.8 & 4.6 & 1.5 & 6.4 & 2.1 & 25.0 \\
\hline \multicolumn{2}{|c|}{ En Yüksek Değer : } & 18.0 & 20.2 & 18.9 & 3.2 & 5.2 & 3.7 & 38.0 & 100.2 & 60.8 & 5.2 & 3.0 & 3.8 & 10.5 & 2.0 & 8.0 & 2.7 & 350.0 \\
\hline \multicolumn{2}{|c|}{ Standart Sapma : } & 1.3 & 2.3 & 1.2 & 0.6 & 0.7 & 0.4 & 9.4 & 22.8 & 12.3 & 0.7 & 0.4 & 0.4 & 1.6 & 0.1 & 0.4 & 0.1 & 89.2 \\
\hline \multicolumn{2}{|c|}{$\begin{array}{l}\text { Değişim } \\
\text { Katsayısı (\%) }\end{array}$} & 8.1 & 13.2 & 7.3 & 36.2 & 18.1 & 14.4 & 45.1 & 55.3 & 39.5 & 32.4 & 18.4 & 19.8 & 20.6 & 4.8 & 6.1 & 6.5 & 66.6 \\
\hline
\end{tabular}

Çizelge 5. Anadolu Pembesi-2002 çeşidi ve mutantların 2014 ve 2015 yılları ana sap uzunluğu, ana sap sayısı, bitkideki bakla sayısı, bakladaki tane sayısı, doğal bitki boyu, ana sap kalınlığı, bakla eni, bakla boyu, yeşil ot verimi değerleri ile basit istatistik analiz sonuçları

\begin{tabular}{|c|c|c|c|c|c|c|c|c|c|c|c|c|c|c|c|c|c|c|}
\hline \multirow[b]{2}{*}{ No } & \multirow{2}{*}{ Çeşit / Hat } & \multicolumn{3}{|l|}{ ASU } & \multicolumn{3}{|l|}{ ASS } & \multicolumn{3}{|l|}{ BBS } & \multicolumn{3}{|l|}{ BTS } & \multirow{2}{*}{\begin{tabular}{|l|} 
DBB \\
2015 \\
\end{tabular}} & \multirow{2}{*}{$\begin{array}{l}\text { ASK } \\
2015\end{array}$} & \multirow{2}{*}{$\begin{array}{l}\mathrm{BE} \\
2015\end{array}$} & \multirow{2}{*}{$\begin{array}{l}\text { BB } \\
2015\end{array}$} & \multirow{2}{*}{$\frac{\text { YOV }}{2015}$} \\
\hline & & 2014 & 2015 & Ort. & 2014 & 2015 & Ort. & 2014 & 2015 & Ort. & 2014 & 2015 & Ort. & & & & & \\
\hline 1 & $\begin{array}{l}\text { Anadolu } \\
\text { Pembesi-2002 }\end{array}$ & 17.2 & 18.9 & 18.0 & 2.0 & 5.0 & 3.5 & 26.3 & 62.6 & 44.5 & 2.0 & 1.8 & 1.9 & 8.3 & 1.9 & 7.0 & 2.1 & 130.0 \\
\hline 2 & AP604 & 16.0 & 21.5 & 18.8 & 1.2 & 3.2 & 2.2 & 27.0 & 28.4 & 27.7 & 2.2 & 2.0 & 2.1 & 10.0 & 1.7 & 7.4 & 2.2 & 85.0 \\
\hline 3 & AP605 & 13.9 & 18.6 & 16.3 & 1.4 & 3.4 & 2.4 & 21.4 & 54.2 & 37.8 & 2.2 & 2.8 & 2.5 & 9.1 & 1.8 & 6.6 & 2.3 & 95.0 \\
\hline 4 & AP801 & 16.2 & 17.4 & 16.8 & 2.0 & 2.4 & 2.2 & 25.8 & 30.8 & 28.3 & 2.0 & 1.6 & 1.8 & 12.0 & 1.6 & 6.4 & 2.0 & 155.0 \\
\hline 5 & AP804 & 17.1 & 18.8 & 18.0 & 1.6 & 3.6 & 2.6 & 16.6 & 36.6 & 26.6 & 2.0 & 1.8 & 1.9 & 10.5 & 1.8 & 6.6 & 2.1 & 95.0 \\
\hline 6 & AP805 & 17.5 & 17.7 & 17.6 & 1.6 & 4.4 & 3.0 & 29.8 & 30.2 & 30.0 & 2.0 & 2.0 & 2.0 & 7.9 & 1.8 & 6.4 & 2.0 & 75.0 \\
\hline 7 & AP807 & 13.2 & 16.9 & 15.1 & 1.2 & 3.8 & 2.5 & 19.4 & 48.4 & 33.9 & 1.6 & 1.4 & 1.5 & 6.8 & 1.8 & 7.2 & 2.0 & 50.0 \\
\hline 8 & AP808 & 14.7 & 16.8 & 15.8 & 1.2 & 3.0 & 2.1 & 13.8 & 54.0 & 33.9 & 1.6 & 2.2 & 1.9 & 8.0 & 1.7 & 6.4 & 2.1 & 20.0 \\
\hline 9 & AP8011 & 16.0 & 18.1 & 17.1 & 1.0 & 3.4 & 2.2 & 12.8 & 31.0 & 21.9 & 1.8 & 2.3 & 2.1 & 8.1 & 1.7 & 7.0 & 2.1 & 70.0 \\
\hline 10 & AP1001 & 16.1 & 25.6 & 20.9 & 1.0 & 6.4 & 3.7 & 9.6 & 20.8 & 15.2 & 2.0 & 2.0 & 2.0 & 8.0 & 2.0 & 6.2 & 2.2 & 165.0 \\
\hline 11 & AP1002 & 17.3 & 20.3 & 18.8 & 1.0 & 3.8 & 2.4 & 13.4 & 30.6 & 22.0 & 1.8 & 1.8 & 1.8 & 8.7 & 1.9 & 7.4 & 2.3 & 45.0 \\
\hline 12 & AP1003 & 15.5 & 20.5 & 18.0 & 1.0 & 5.0 & 3.0 & 17.6 & 49.0 & 33.3 & 1.8 & 1.4 & 1.6 & 7.9 & 1.9 & 5.8 & 2.0 & 70.0 \\
\hline 13 & AP1005 & 16.0 & 11.5 & 13.8 & 1.0 & 3.0 & 2.0 & 10.8 & 44.4 & 27.6 & 1.4 & 2.6 & 2.0 & 5.0 & 1.9 & 7.6 & 2.6 & 10.0 \\
\hline \multicolumn{2}{|c|}{ Ortalama } & 15.8 & 18.6 & 17.3 & 1.3 & 3.8 & 2.5 & 18.2 & 38.2 & 28.2 & 1.9 & 2.0 & 1.9 & 8.5 & 1.8 & 6.8 & 2.2 & 77.9 \\
\hline \multicolumn{2}{|c|}{ En Düşük Değer } & 13.2 & 11.5 & 13.8 & 1.0 & 2.4 & 2.0 & 9.6 & 20.8 & 15.2 & 1.4 & 1.4 & 1.5 & 5.0 & 1.6 & 5.8 & 2.0 & 10.0 \\
\hline \multicolumn{2}{|c|}{ En Yüksek Değer } & 17.5 & 25.6 & 20.9 & 2.0 & 6.4 & 3.7 & 29.8 & 54.2 & 37.8 & 2.2 & 2.8 & 2.5 & 12.0 & 2.0 & 7.6 & 2.6 & 165.0 \\
\hline \multicolumn{2}{|c|}{ Standart Sapma } & 1.3 & 3.3 & 1.9 & 0.3 & 1.1 & 0.5 & 6.6 & 11.3 & 6.3 & 0.2 & 0.4 & 0.3 & 1.8 & 0.1 & 0.6 & 0.2 & 46.8 \\
\hline \multicolumn{2}{|c|}{$\begin{array}{l}\text { Değişim } \\
\text { Katsayısı (\%) }\end{array}$} & 8.3 & 18.0 & 10.9 & 25.5 & 28.2 & 19.4 & 36.5 & 29.5 & 22.4 & 13.2 & 21.8 & 13.3 & 21.1 & 7.2 & 8.3 & 8.1 & 60.1 \\
\hline
\end{tabular}

Tarm Beyaz1-98, Oğuz-2002 ve Anadolu Pembesi2002 çeșitlerindeki bulgular, gama 1şını uygulamasının bitkilerde farklı tepkilere ve gelişme farkl1lıklarına sebep olabildiğini belirten Şehirali ve Özgen (2007) ile bazı tahıllardaki klorofil mutasyon sıklığına farklı ploidi seviyelerinin etkisini inceleyen Reddy ve Suganthi (1993)'nin çeşitlerin gama dozlarına olan tepkisinde farklılıklar tespit edilebildiğini belirttikleri çalışmalarıyla benzerlik göstermektedir. Anadolu Pembesi-2002 çeşidinde elde edilen veriler ayrica 
Majeed ve ark. (2010)'nın tere bitkisinde elde ettikleri bazı büyüme parametrelerinin artan gama ışın dozlarıyla azalma eğilimi gösterdiği bulgularıyla uyum sağlamaktadır.

\section{Mutant hatların değerlendirilmesi}

\section{Morfolojik özellikler}

Mutant hatların morfolojik özellikleri ile ot verimiyle ilgili ortalama, en düşük ve en yüksek değerleri, standart sapma ve değişim katsayısı değerleri Çizelge 3, 4 ve 5 'de verilmiştir. Doğal bitki boyu (DBB, cm)

$\mathrm{Bu}$ özellik Tarm Beyazı-98 çeşidinde kontrol uygulamasinda $19.5 \mathrm{~cm}$, mutant hatların ortalamasinda ise $30.0 \mathrm{~cm}$ olmuştur. En düşük değer $19.8 \mathrm{~cm}$ (TB601), en yüksek değer $37.4 \mathrm{~cm}$ 'dir (TB1002) ( Çizelge 3).

$\mathrm{Bu}$ özellik Oğuz-2002 çeşidinde kontrolde $6.1 \mathrm{~cm}$, hatların ortalamasında $7.9 \mathrm{~cm}$ olarak bulunmuştur. En düşük ve en yüksek değer sirasıyla $4.6 \mathrm{~cm}$ (OG1007) ve $10.5 \mathrm{~cm}$ 'dir (OG802) (Çizelge 4).

Aynı özellik Anadolu Pembesi-2002 çeşidinde kontrolde $8.3 \mathrm{~cm}$ olurken hatların ortalamasında $8.5 \mathrm{~cm}$ olarak tespit edilmiştir. En düşük değer $5.0 \mathrm{~cm}$ (AP1005), en yüksek değer ise $12 \mathrm{~cm}$ 'dir (AP801). Özellikle Tarm Beyazı-98'de DBB arttığı görülmüştür (Çizelge 8,10 ve 12) (Çizelge 5).

Ana sap uzunluğu (ASU, cm)

ASU açısından Tarm Beyazı-98 çeşidinde kontrol uygulaması $33.8 \mathrm{~cm}$, hatların ortalaması ise $37.7 \mathrm{~cm}$ olarak saptanmıştır (Çizelge 3). Bu çeşitte en düşük değer $34.4 \mathrm{~cm}$ (TB604), en yüksek değer $41.0 \mathrm{~cm}$ 'dir (TB602). Oğuz-2002'de kontrol $15.2 \mathrm{~cm}$, hatların ortalaması $16.7 \mathrm{~cm}$ olmuştur (Çizelge 4). Aynı çeşitte en düşük ve en yüksek değer sırasıyla $14.3 \mathrm{~cm}$ (OG1007) ve $18.9 \mathrm{~cm}$ 'dir (OG806). Anadolu Pembesi-2002'de ise kontrol $18.0 \mathrm{~cm}$ olurken hatların ortalamaları $17.3 \mathrm{~cm}$ bulunmuştur ( Çizelge 5). Bu çeşitte en düşük değer $13.8 \mathrm{~cm}$ (AP1005), en yüksek değer ise $20.9 \mathrm{~cm}$ 'dir (AP1001).

Doz artışları ASU üzerinde çeşitlere göre değişik etki yapmış olup bu etki Tarm Beyazı-98 ve Oğuz2002'de artış, Anadolu Pembesi-2002'de ise düşüş, şeklinde görülmüştür (Çizelge 3, 4 ve 5).

\section{Ana sap kalınlığı (ASK, mm)}

Bu özellik açısından Tarm Beyazı-98, Oğuz-2002 ve Anadolu Pembesi-2002'de kontrol ve hat ortalamaları sirayla 2.3 ve $2.3 \mathrm{~mm} ; 1.8$ ve $1.8 \mathrm{~mm} ; 1.9$ ve $1.9 \mathrm{~mm}$ olarak tespit edilmiştir (Çizelge 3, 4 ve 5). Tüm çeşitlerde ASK bakımından farklılık saptanmamıştır.

Ana sap sayısı (ASS, adet)

Bu özellik açısından Tarm Beyazı-98, Oğuz-2002 ve Anadolu Pembesi-2002'de kontrol ve hat ortalamaları sirayla 3.2 ve 3.3 adet; 2.5 ve 2.8 adet; 3.5 ve 2.5 adet olarak bulunmuştur (Çizelge 3, 4 ve 5 . Bu çalışmada doz uygulamaları incelenen çeşitlerin $M_{4}$ ve $M_{5}$ bitkilerinde bu özellik üzerinde farklı bir etki yapmamıştır

\section{Bitkideki bakla sayısı (BBS, adet)}

Çeşitlerde BBS Tarm Beyazı-98, Oğuz-2002 ve Anadolu Pembesi-2002'de kontrol ve hat ortalamaları sirayla 14.9 ve 19.4 adet; 36.5 ve 31.3 adet; 44.5 ve 28.2 adet olarak saptanmıştır (Çizelge 3, 4 ve 5). $\mathrm{Bu}$ çeşitlerde en düşük ve en yüksek değer sırayla 12.4 adet (TB801) ve 30.7 adet (TB604); 11.9 (OG1007) ve 60.8 adettir (OG805); 15.2 adet (AP1001) ve 37.8 adet (AP605) olmuştur.

Khan ve Goyal (2009) EMS (Ethyl Methane Sulphonate) ve gama 1şını mutagenleri uyguladıkları maş fasulyesi üzerinde bitki başına dal sayısı, bakla sayısı ve tohum verimi gibi farklı nicel özelliklerde genetik çeşitliliği oluşturmak ve verimi artırmak için seleksiyon çalışmaları yapmışlardır. $\mathrm{M}_{5}$ generasyonunda inceledikleri özelliklerde ve genetik parametrelerde kontrole göre mutantların ortalama değerlerinin daha yüksek olduğunu ve mutantların genetik avantajları ile yüksek kalıtım dereceleriyle gelecek generasyonlarda ilerleme sağlanabileceğini belirtmişlerdir. $\mathrm{Bu}$ çalışmadaki gama 1şını dozlarının Tarm Beyazı-98 çeşidinin BBS üzerindeki etkisi Khan ve Goyal (2009)'in maş fasulyesi üzerinde yaptıkları çalışmayla benzer sonuçlar göstermiş̧ir.

Tarm Beyazı-98 ile Oğuz-2002 çeşitlerine uygulanan gama 1şın dozları arasında önemli bir farklılık bulunmamasına rağmen, mutagen uygulamalarının BBS arttırıcı yönde etki ettiği saptanmıştır. Tarm Beyazı-98 ve Oğuz-2002 mutantlarındaki bu artışın bir boğumdan çıkan fertil bakla sayının artmasına bağlı olduğu tespit edilmiştir. $\mathrm{Bu}$ iki çeşit de genellikle bir boğumdan bir ya da iki adet bakla oluşmaktadır (Şekil 1 ve Şekil 2). $M_{4}$ ve $M_{5}$ generasyonunda gama 1şı dozlarının Oğuz-2002 mutantlarında bir boğumdan üç adet, Tarm Beyazı-98 mutantlarında ise bir boğumdan üç ve dört adet bakla oluşumuna neden olduğu gözlenmiştir (Şekil 3 ve Şekil 4). Bu durum Aleksieva ve Naidevova (2012)'nın yaygın fiğde kimyasal mutagen uygulaması ile elde ettikleri bakla sayısındaki artışla, Wani ve Khan (2006)'in maş fasulyesindeki kimyasal mutagen uygulamalarıyla tespit ettikleri bitki başına boğum sayısı ve tohum verimindeki artışla da benzerdir.

Anadolu Pembesi-2002 çeşidinde ise gama ışın dozlarının belirgin bir şekilde BBS azaltıcı etkide bulunduğu görülmüş̧ür. 


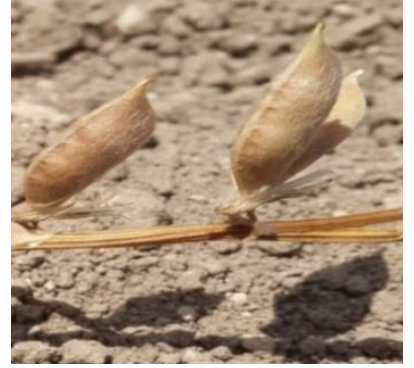

Şekil 1. Oğuz-2002 çeşidinde bakla sayısı

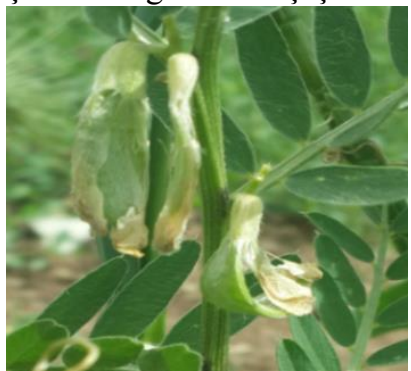

Şekil 2. Tarm Beyazı-98 çeşidinde bakla sayısı

Bakla eni (BE, mm) ve bakla boyu $(\mathrm{BB}, \mathrm{cm})$

Çeşitlerde BE Tarm Beyazı-98, Oğuz-2002 ve Anadolu Pembesi-2002'de kontrol ve hat ortalamaları sirayla $7.0 \mathrm{~mm}$ ve $7.2 ; 7.0$ ve $7.0 \mathrm{~mm} ; 7.0$ ve $6.8 \mathrm{~mm}$ olarak tespit edilmiştir (Çizelge 3, 4 ve 5). Aynı çeşitlerde BB kontrol ve hat ortalamaları sırayla 2.6 ve $2.9 \mathrm{~mm} ; 2.0$ ve $2.2 \mathrm{~mm} ; 2.1$ ve $2.2 \mathrm{~mm}$ olarak saptanmıștır.

Bakladaki tane sayısı (BTS, adet)

Çeşitlerde BTS Tarm Beyazı-98, Oğuz-2002 ve Anadolu Pembesi-2002'de kontrol ve hat ortalamaları sirayla 4.7 adet ve 4.5 adet; 1.8 ve 2.1 adet; 1.9 ve 1.9 adet olarak saptanmıştır.

Tarımsal özellik

Yeşil ot verimi (YOV, $\mathrm{g} \mathrm{p}^{-1}$ )

Çeşitlerde YOV Tarm Beyazı-98, Oğuz-2002 ve Anadolu Pembesi-2002'de kontrol ve hat ortalamaları sirayla 655.0 g p-1 ve 910.7 g p-1; 125.0 g p-1 ve 134.1 g p-1; 130.0 g p-1 ve 77.9 g p-1 olarak tespit edilmiştir (Çizelge 3, 4 ve 5). Aynı özelliğin bu çeşitlerde en düşük ve en yüksek değerleri sirayla $500.0 \mathrm{~g} \mathrm{p}-1$ (TB803) ve $1425.0 \mathrm{~g} \mathrm{p}-1$ (TB1007); $25 \mathrm{~g} \mathrm{p}-1$ (OG801) ve $350.0 \mathrm{~g} / \mathrm{p}$ (OG802); $10.0 \mathrm{~g} / \mathrm{p}$ (AP1005) ve $165.0 \mathrm{~g} / \mathrm{p}$ (AP1001) olarak saptanmıştır.

Nasare (2011) fesleğen bitkisine uyguladığı fiziksel ve kimyasal mutagenlerin morfolojik çeşitlilik

\section{SONUC}

$\mathrm{Bu}$ çalışma da elde edilen sonuçlar aşağıda özetlenmiştir.

\section{Doz değerlendirmesi}

Gama dozlarının BBS üzerine etkileri kontrol ve mutantlarda farklı olmuştur. Anadolu Pembesi-2002 hatlarında kontrole göre doz oranı arttıç̧a BBS azalırken Tarm Beyazı-98 çeşidinde tüm gama dozları BBS'nı artmıştır. Oğuz-2002 çeşidinde ise kontrole göre 60 ve 80 Gy gama dozu uygulamaları BBS'nı artırırken 100 Gy dozunun azalmalara neden olduğu saptanmıştır. Genel bir değerlendirme yapıldığında, $M_{4}$ ve $M_{5}$

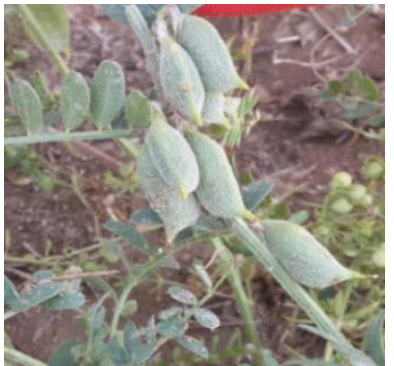

Şekil 3. OG805 hattında bakla sayısı

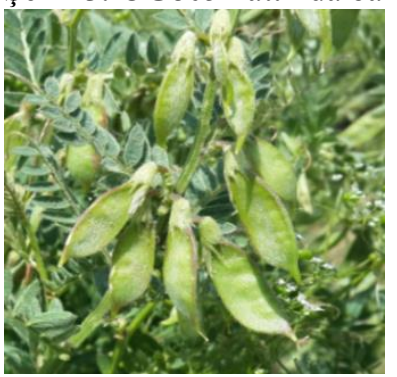

Şekil 4. TB603 hattında bakla sayısı

oluşturmada etkili olduğunu ve yüksek verim ile erken çiçeklenme açısından bitki ıslahında kullanılabilecek önemli mutanlar elde edildiğini bildirmektedir. Mutagen uygulamaları ile elde edilmiş mutant bitkilerimiz morfolojik çeşitliliğin oluşturulması ve yüksek verim yönüyle benzerdir.

Bitki tohumlarına uygulanan farklı gama ışını dozlarının $\mathrm{M}_{4}$ ve $\mathrm{M}_{5}$ bitkilerinde incelenen bazı morfolojik özelliklere göre etkisi çeşitler arasında farklılık göstermektedir. İncelenen karakterler bakımından çeşitler ile hatlar arasında farklılıkların olduğu tespit edilmiştir.

$\mathrm{Bu}$ sonuçlar "farklı bitki türleri ve aynı tür içerisindeki farklı genotipler herhangi bir mutagene karşı farklı hassasiyetlere sahiptir" (Wehr 1987) görüşüyle uyumludur.

Maş fasulyesinde kantitatif karakterler (dal sayısı, bakla sayısı, bakla uzunluğu, bakladaki tane sayısı, 100 tane ağırlığı ve toplam bitki verimi) üzerinde gama ışınının mutagenik etkilerini inceleyen Khan (1982) da genetik çeşitliliğin ve kalıtım değerlerinin tüm karakterlerde arttığını fakat farklı mutagenik uygulamalara özelliklerin farklı cevap verdiğini belirtmektedir. Bulgularımızda da uygulanan gama 1şınlarının üç Macar fiğ çeşidinde incelenen özellikler üzerindeki etkisi farklılık göstermiştir generasyonunda incelenen özelliklerin çoğunda farklılıkların Oğuz-2002 çeşidinde 60 ve 80 Gy, Anadolu Pembesi-2002 ile Tarm Beyazı-98 çeşitlerinde 60 ve 100 Gy dozlarında olduğu, belirlenmişstir.

\section{Mutant hatların değerlendirilmesi}

Uygulanan gama 1şınları ile Tarm Beyazı-98 çeşidinde BBS 12.4-30.7 adet arasında değişim göstermiştir. Kontrol grubu ise 14.9 adet olarak bulunmuştur. Bu özellik Oğuz-2002 çeşidinde ise 11.960.8 arasında değişim gösterirken kontrol uygulamasında 36.5 adet olarak bulunmuştur. Anadolu Pembesi-2002 çeşidinde BBS 15.2-44.5 adet arasında 
değişmiş ve en yüksek değer kontrol grubundan alınmıştır.

Mutagen uygulamalarının $\mathrm{M}_{4}$ ve $\mathrm{M}_{5}$ aşamalarındaki Macar fiği bitkisinde çeşitlere göre farklı etki yaptığ 1 görülmüştür. Tarm Beyazı-98 ve Oğuz-2002 çeşitlerinde gama ışın dozlarının olumlu etkisi görülürken Anadolu Pembesi-2002 çeşidinde ise olumsuz etki görülmüştür.

Genel olarak gama ışını uygulamalarının $\mathrm{M}_{4}$ ve $\mathrm{M}_{5}$ generasyonunda incelenen bitki karakterleri üzerindeki etkileri çeşitlere göre değişmiş ve yine bu uygulamalar incelenen özellikler üzerinde de farklı etki göstermiştir. Ayrıca $M_{4}$ ve $M_{5}$ 'de incelenen özelliklerde gama 1şınlarının önemli değişikliklere neden olduğu tespit edilmiştir.

\section{KAYNAKLAR}

Akbay G 1988. Farklı EMS (Ethyl Methane Sulphonate) dozlarının uygulandığ $\breve{1}_{1}$ Tokak 157/57 (Hordeum vulgare L.) iki sıralı arpa çeşidi tohumlarının farklı ortam ve farklı sürelerle bekletilmesinin $\mathrm{M}_{1}$ bitkilerinin bazı özellikleri üzerindeki etkileri. A.Ü. Ziraat Fakültesi Yayınları:1070, Bilimsel Araştırma ve İncelemeler: 573

Aleksieva A, Naidevova G 2012. A new mutant spring forage vetch line (Vicia sativa ssp. sativa L.) with increased pod number per fertile node. Banat's Journal of Biotechnology, DOI:10.7904/2068-4738III(6)-5

Anonim 2016a. Meteoroloji Genel Müdürlüğü.

Anonim 2016b. Toprak Gübre ve Su Kaynakları Merkez Araştırma Enstitüsü Müdürlüğü.

Artık C, Pekşen E 2006. Gama 1şınlamasının $\mathrm{M}_{2}$ generasyonunda bakla (Vicia faba L.)'nın tane verimi ve bazı bitkisel özellikleri üzerine etkileri. J. Of Fac. Of Agric., OMU, 21(1):95-104

Khan I.A 1982. Variation in quantitative characters of mung bean (Phaseolus aureus Roxb.) after seed irradiation. Bot. Bull. Academia Sinica 23: 105-118.
Khan S, Goyal S 2009. Improvement of mungbean varieties through induced mutations. African Journal of Plant Science Vol. 3 (8), pp. 174-180, India.

Majeed A, Ahmad H, Khan A.U.R, Muhammad Z 2010. Gamma irradiation effects on some growth parameters of Lepidium sativum L. ARPN Journal of Agricultural and Biological Science. Vol. 5, No:1.

Maluszynski M, Nichterlein L, Zanten V, Ahloowalia B.S 2000. Officially released mutant varieties-The FAO/IAEA DATABASE, No: 12

Nasare P.N 2011. Characterisation of induced morphological mutants in Ocimum sanctum Linn. Online International Interdisciplinary Research Journal,\{Bi-Monthly\}, ISSN2249-9598, Volume-I, Issue-II.

Olgun M, Ayter N.G, Kutlu İ, Başçiftçi Z.B 2012. Farklı gamma ışını dozlarının ekmeklik buğdayda fide gelişimi üzerine etkisi. Süleyman Demirel Üniversitesi Ziraat Fakültesi Dergisi 7(2): 73-80.

Ramados B.R, Ganesamurthy K, Angappan K, Gunasekaran M 2014. Evaluation of effect of gamma rays on sesame genotype TTVS 51 and TTVS 19 in $\mathrm{M}_{1}$ generation. International Journal of Development Research Vol. 4, Issue, 2, pp. 273-277.

Reddy V.R.K, Suganthi C.P 1993. Effect of different ploidy levels on chlorophyll mutations frequency in some cereals. Advances in Plant Sciences, 6:1, 178191.

Şehirali S, Özgen M 2007. Bitki Islahı. Ankara Üniversitesi Ziraat Fakültesi Yay. No:1553, Ankara

Tosun F 1974. Baklagil ve Buğdaygil Yem Bitkileri Kültürü. Atatürk Üniversitesi Yayın No:242, Ziraat Fakültesi Yayın No:123, Ders Kitapları Serisi No:8, Erzurum

Wani M.R, Khan S 2006. Estimates of genetic variability in mutated populations and the scope of selection for yield attributes in Vigna radiata (L.) Wilczek. Egyptian Journal of Biology. Vol. 8, pp 16.

Wehr W.R 1987. Principles of Cultivar Development Theory and Technique. Macmillian Pub. Co., 525, New York 